\title{
PSIQUIATRIA, SAÚDE MENTAL E BIOPODER: VIDA, CONTROLE E MODULAÇÃO NO CONTEMPORÂNEO
}

\author{
Cristina Rauter \\ Paulo de Tarso de Castro Peixoto
}

\begin{abstract}
RESUMO. O trabalho consiste em uma análise sobre os impasses que enfrentam atualmente as instituições de saúde mental no contexto da reforma psiquiátrica brasileira. Os dispositivos de saúde mental podem funcionar como uma nova expansão da psiquiatria no espaço extramuros, agindo com métodos mais sutis de controle e operando tanto a partir das instituições de saúde quanto da própria subjetividade dos usuários. São utilizadas referências do campo da filosofia na construção de uma clínica transdisciplinar capaz de incluir os aspectos políticos envolvidos no atendimento em saúde mental, superando os impasses que levam a práticas redutoras e estigmatizantes.
\end{abstract}

Palavras-chave: Subjetividade contemporânea; clínica transdisciplinar; reforma psiquiátrica..

\section{PSYCHIATRY, MENTAL HEALTH AND BIO-POWER: LIFE, CONTROL AND MODULATION IN CONTEMPORARY SOCIETY}

\begin{abstract}
An analysis of the impasses faced by Brazilian mental health institutions in the context of contemporary Brazilian psychiatric reform is provided. The institutions of mental health may operate as a new expansion of psychiatry outside the asylum, acting through more subtle methods of social control working in mental health institutions themselves or within the subjectivity of the clientele. References from the field of philosophy are employed to build a transdisciplinary approach. Political aspects involved in mental health practices may than be taken into consideration, overcoming the obstacles present in mental health theories and practices and building innovative perspectives.
\end{abstract}

Key words: Contemporary subjectivity; transdisciplinary clinics; psychiatric reform.

\section{PSIQUIATRÍA, SALUD MENTAL Y BIO-PODER: VIDA, CONTROL Y MODULACIÓN EN EL CONTEMPORÁNEO}

RESUMEN. Un análisis acerca de los obstáculos presentes en las instituciones de salud mental en el contemporaneo y en el contexto de la reforma psiquiátrica brasileña. Los dispositivos de salud mental pueden funcionar como una nueva expansión de la psiquiatría fuera del espacio del asilo actuando por métodos mas sutiles de control. Estos métodos operan tanto a partir de las propias instituciones de salud cuanto a partir de la subjetividad de los usuarios. Son utilizadas referencias del campo de la filosofía en la construcción de uma clínica transdisciplinar capaz de incluir los aspectos políticos envueltos en la asistencia en salud mental, superando los obstáculos que llevan a prácticas reductoras y estigmatizantes.

Palabras-clave: Subjetividad contemporânea; clínica transdisciplinar; reforma psiquiátrica.

* Doutora em Psicologia Clínica, Professora Associada I do Departamento de Psicología da Universidade Federal Fluminense.

\# Mestre em Psicologia, Musicoterapeuta do Programa de Saúde Mental da Secretaria Especial de Saúde de Macaé, Supervisor do Capsi Macaé (RJ).

1 Classificação de Transtornos Mentais e de Comportamento da CID 10 da Organização Mundial de Saúde (OMS), publicada na década de 90. 


\section{DA VIDA PSICOPATOLOGIZADA}

Vivemos num cenário no qual se instala um novo boom da psiquiatria, desta vez dizendo respeito não tanto aos psicóticos ou loucos, mas aos "normais". A partir da nosografia psiquiátrica - que é tomada como referência nos manuais psiquiátricos e orienta principalmente o CID-10 $10^{1}$, a psiquiatria dita científica pretende realizar, com a designação "transtorno", uma descrição finalmente "neutra" da doença mental (Aguiar, 2004). Seu sonho é tornar a descrição das patologias psíquicas a tal ponto objetiva que um profissional da China e um dos Estados Unidos possam chegar a um mesmo diagnóstico e à indicação de um mesmo remédio. Denominações que não preenchiam esse ideal de cientificidade foram descartadas, tais como as terminologias outrora tão frequentes, "psicose" ou "neurose". Outra característica dessa vertente da psiquiatria é permitir que médicos não psiquiatras possam prescrever com mais facilidade a medicação adequada, pois diante de um transtorno objetivamente definido e universalmente observável, qualquer profissional médico pode se habilitar a prescrever o medicamento correto. Assim, hoje em dia, podemos ir ao clínico geral ou ao ginecologista, ou ainda ao reumatologista, e de lá sair medicados com um antidepressivo. Por exemplo, a condição denominada "fibromialgia", caracterizada por dores em todo o corpo, é um dos casos em que um reumatologista ou ortopedista pode prescrever um antidepressivo, não raro com a advertência ao paciente de que deverá tomá-lo "por toda a vida”, já que se trata de doença incurável. É comum encontrarmos em revistas - especializadas ou não - referências a experiências classificadas como transtorno de pânico ou transtorno obsessivocompulsivo nas quais alguns se reconhecem ou diagnosticam parentes próximos.

Impressionante é também o que se processa no campo da saúde escolar. Crianças-problema, outrora apenas encaminhadas da escola para um especialista não-médico, em geral um psicólogo ou fonoaudiólogo, atualmente têm como destino principal a intervenção médica. É feito com frequência o diagnóstico do "transtorno do déficit da atenção" (TDA), combinado ou não com hiperatividade (TDAH), sendo a terapêutica privilegiada a medicamentosa. Os pais costumam ser advertidos de que as crianças acometidas dessas patologias podem ser rebeldes e questionadoras.

Já o transtorno antissocial (TAS) refere-se a uma patologia que consiste justamente no cometimento de desobediências e rebeldias, ou mesmo de crimes. Seus 'sintomas' se iniciam na infância, associados ao fracasso escolar e/ou ao questionamento da autoridade, e prolongam-se por toda a vida, numa série de comportamentos oposicionistas no trabalho e na família. A condição é considerada incurável por meio dos meios psicoterápicos tradicionais Estes comportamentos têm como principal terapêutica, em especial quando se trata de alguém condenado pelo cometimento de crime, o envio do "paciente" a "estabelecimento prisional adequado". Para os apenados acometidos de TAS, não há indicação de nenhum programa ressocializador ou terapêutico, medida considerada inadequada, já que não há esperança de alteração do quadro por meio dela. Segundo Morana (2003), a psicoterapia não exerce nenhuma influência sobre o curso da doença. Alguns autores referem que, "inexplicavelmente", o transtorno costuma ocorrer mais frequentemente nos bairros pobres, e, não por acaso, nas prisões

Não esqueçamos também do campo dos distúrbios sexuais, nos quais medicamentos operam transformações nas definições até pouco tempo atrás vigentes quanto ao comportamento sexual. Uma sexualidade performática e dotada de eficácia - tal é a promessa dos laboratórios. Também os hormônios, sobretudo sua escassez, constituem-se no diagnóstico proferido para perturbações da vida amorosa. As percepções e sensações não são mais tomadas, dentro dessa nova lógica, como os elementos principais a partir dos quais nos orientamos para lidar com os amores, seus riscos e suas vicissitudes, ou com as transformações do corpo pela passagem do tempo. Há sempre um outro plano, o do organismo biológico, capaz de dar inteligibilidade ao que se passa e, por sua vez, sempre um especialista a fornecer o medicamento adequado para corrigir um transtorno.

\section{INVISIBILIDADE E MOLECULARIZAÇÃO DOS DISPOSITIVOS DE PODER}

O campo da produção de subjetividades encontra-se, no contemporâneo, atravessado pela 
problemática da desterritorialização, como apontaram Deleuze e Guattari em $O$ Anti-Édipo (1974). Se de um lado a desterritorialização possibilita e intensifica processos que se caracterizam pela criação de múltiplos modos de existir e de subjetividades singulares, por outro lado, poderosos dispositivos de controle perpassam também o campo social. E não se pense que tais dispositivos agem de modo repressivo, operando a partir de lógicas binárias do tipo opressoroprimido. Linhas moleculares, linhas segmentares e linhas de fuga constituem-se em emaranhados complexos de saber-poder, tornando indefinível a direção a tomar na construção de dispositivos de resistência (Deleuze \& Parnet, 1977). Entendemos que a psiquiatria biológica atual se insere no quadro desses poderosos dispositivos de controle contemporâneos, cuja marca principal é seu caráter abrangente e global. Seu arsenal farmacológico já não se dirige apenas aos "loucos", mas predominantemente aos "normais", ou seja, a todos. Suas definições "objetivas" tomam o cotidiano como foco de intervenção: a insônia, os conflitos entre pais e filhos, os amores muito intensos, as pequenas tristezas e desânimos, as dores difusas, patologias sempre novas, a merecerem novas descrições e previsões de incurabilidade. Por outro lado, promete-se uma cura sintomática rápida caso se faça uso do medicamento correto. É na consulta médica que se edificará o lugar e a carreira daqueles que, por aderirem sem questionar aos pontos de vista cientificistas, doravante receberão o seu novo estatuto: o de doente-anormal.

Sim, é possível uma vida normal, desde que o paciente faça uso da medicação "por toda a vida", tal é o vaticínio proferido com frequência nas consultas médicas. Tanto a previsão de incurabilidade quanto da cura pelo uso perene de medicação são enunciações de saberes que definem o futuro como se este já estivesse dado.

Ademais, não são apenas os especialistas que diagnosticam. Podemos ser diagnosticados por colegas, ou até por um leigo que tenha lido alguma revista ou pesquisado na internet, onde sítios explicativos da indústria farmacêutica podem ser consultados por qualquer um. Assim, cada um que entra numa instituição de saúde mental será modelado pela lógica que ali circula, mas pode já estar modelado, antes mesmo de entrar, pelas lógicas já presentes no campo social. A experiência sensível de cada um é tornada secundária em proveito dessa lógica de "saúde mental" que se espalha nas experiências da cidade, apoiada em classificações nosológico-nosográficas veiculadas por instâncias de saber-poder. Psiquiatria, psicologia e outros saberes operam essa redução a categorias do negativo daquilo que emerge enquanto experiência subjetiva complexa e singular.

A lógica da saúde mental se espalha como a lógica do capitalismo, que com a sua força de afecção operando sobre o desejo, tenta capturar cada um, não por meio da disciplina que modela e dociliza, mas, sobretudo, pela produção de novas modulações que têm efeitos desnorteadores sobre as subjetividades. Já não é possível localizar o ponto de incidência do poder a ser combatido, pois o poder está dissolvido em inúmeras experiências cotidianas. O saber das pessoas comuns também está impregnado pela ladainha do saber biomédico. Utilizamos aqui o termo "ladainha" para enfatizar seu caráter repetitivo, de refrão, que, agindo sobre as subjetividades desterritorializadas do capitalismo atual, constituem-se em poderosos dispositivos de captura. Os gestos, os movimentos, as palavras, as ideias, os sonhos, os afetos, tornaram-se objeto de uma lógica cientificista.

\section{DAS TECNOLOGIAS DE DIAGNÓSTICOS E A PRODUÇÃO DE OBJETOS - ALGUMAS RESSONÂNCIAS HISTÓRICAS}

O movimento da Inquisição, no século XIII, prescrevia com suas bulas - não científicas, mas, sobretudo, religiosas - quais seriam os objetos a serem diagnosticados, as prescrições e, por conseguinte, as evoluções de cada caso (Szasz, 1978). As mulheres consideradas bruxas e os cristãos hereges, juntamente com os judeus, eram os seus objetos. O Malleus Malleficarum - o malho das bruxas - era o manual para diagnóstico e descrição dos desvios em relação à norma religiosa.

Diferentes práticas de controle social em épocas diferentes produzem os objetos sobre os quais operam. Esses seus objetos-alvo não preexistiam a essas práticas, mas foram produzidos por elas. Assim, a inquisição não pode ser pensada sem suas bruxas, o movimento do alienismo sem 
seus alienados, a medicina sem seus pacientes ou o movimento de saúde mental sem seus usuários.

A psiquiatria atual segue sendo um saber fundamentalmente classificatório e tem elaborado classificações que pretendem, como dissemos, ser objetivas e universais. Ainda hoje segue a psiquiatria sendo um tipo especial de medicina muito mais descritiva que explicativa, uma medicina que nunca encontrou verdadeiramente seu corpo, embora adote atualmente um discurso que se pretende biológico e genético. Para Hochmann (1971), é a tríplice determinação descritiva, prescritiva e comunicativa que torna justificável o uso da psiquiatria pelos especialistas. A lógica psiquiátrica se esforça para estruturar o real, tal como o astrônomo que descobre ordem na desordem aparente do espaço. Essa lógica é prescritiva, ou seja, permitir-se-á, através dela, fundamentar o tratamento. Para que o tratamento seja específico, é mister isolar a forma patológica. A psiquiatria possui também uma função comunicativa, pois é por meio da troca de informações entre especialistas, a ser propagada no tecido social, que este saber atinge os diferentes profissionais do campo das ciências humanas e também a população leiga.

Em rigor, as justificativas descritivas, prescritivas e comunicacionais ganham a sua consistência não apenas enquanto ferramentas discursivas dos especialistas. Essas mesmas ferramentas invadem o plano das coletividades no contemporâneo. Será preciso fazer emergir verdades científicas como universais. Assim como uma usina fabrica seus produtos, será preciso produzir os sujeitos a serem classificados pela razão nosográfico-nosológica.

Seria ingênuo considerar que os conceitos produzidos pelas práticas psiquiátricas tenham sido absorvidos nas experiências da cidade de forma passiva. Determinadas condições históricas permitiram a contínua psicopatologização do corpo, da diferença e do desvio na contemporaneidade. A crença nos discursos científicos produtores de verdades universais se edificou numa tessitura complexa de relações, onde teremos como elemento constituinte uma "superfície de emergência" (Foucault, 2005, p. 74). Superfície constituída pela família, pelas redes de vizinhança, pelo meio do trabalho, pela comunidade religiosa, pela comunidade literária, com seus escritos poéticos sobre o desvio e a diferença, dentre outras superfícies. Superfície onde se tecerá - produzindose e reproduzindo-se num feixe de relações desde o século XIX - a emergência do saber psiquiátrico como o mandatário legítimo para encontrar e tratar os virtuais desvios que escapavam à média social.

Será na superfície das relações constitutivas do campo social que se reproduzirá a emergência da racionalização, dos códigos conceituais, das teorias, recebendo o estatuto de verdade. Seguindo esta perspectiva, teremos nas "instâncias de delimitação" (Foucault, 2005) a instituição da psiquiatria como conjunto de práticas e de saberes sobre o corpo da loucura, regulamentada pela corporação dos indivíduos que compõem o corpo médico como saber legitimado e reconhecido pela opinião pública, pela justiça e pelo Estado. A loucura e a diferença ganharão doravante a marca patológica de uma instância científica que as rastreia, designa, distingue, nomeia e transforma em objeto científico. Não apenas a medicina desempenhou este papel. $\mathrm{O}$ aparelho jurídico legitimou a alienação mental através da crença na irresponsabilidade do louco infrator, e no uso de noções como as de crime passional, hereditariedade e periculosidade (Foucault, 2005, p. 47). Por sua vez, a autoridade religiosa atuará também na delimitação das experiências, separando o que é místico do que é patológico, o sobrenatural do anormal.

Será nesta esfera produtora de racionalizações sobre o corpo do desvio e da diferença - efetuada pelas instâncias de delimitação - que encontraremos a "grade de especificações" enquanto tecido composto por sistemas que, por definição, separam, opõem, especificam, agrupam, e classificam os diferentes desvios. Modos de ser se tornam, dessa maneira, objetos do discurso psiquiátrico; mas para que esse discurso adquirisse a hegemonia que detém no contemporâneo foi preciso que se produzisse um conjunto de relações relações recíprocas entre as instâncias de emergência, de delimitação e de especificação. As condutas transgressoras puderam se tornar objetos de saber a partir da produção de uma grade de especificações psiquiátricas e de categorias penais que se deu a partir dos interrogatórios judiciários e policiais e da pesquisa dos antecedentes históricos e biográficos presentes nos questionários médicos e nos exames clínicos. 
Os feixes de relações de poder que constituíram o discurso psiquiátrico legitimaram-no como universal e absoluto, constituindo-o como um entrelaçamento entre as normas familiares, penais e sexuais e o comportamento dos indivíduos. Determinados comportamentos sociais que se diferenciam da média são dessa forma capturados por esse "filtro" operado pelas formações discursivas médicas e jurídicas, garantindo a produção dos objetos científicos a partir das superfícies da família, das redes de vizinhança, das escolas, dos presídios, do trabalho, da comunidade religiosa e de outras experiências coletivas. Tratase da produção e reprodução de formações discursivas estabelecidas num feixe complexo de relações, fazendo com que o racionalismo científico ganhasse um lugar central no que diz respeito à gestão da vida no contemporâneo.

\section{SAÚDE MENTAL E SEUS OBJETOS DE TRABALHO}

Voltando ao caso específico das instituições de saúde mental, podemos dizer que as experiências sensíveis dos usuários, quando reduzidas às unidades abstratas dos conceitos psicopatológicos, transformam-se em "questões de saúde mental" ou em sintomas psicopatológicos. Desse modo, como assinalamos, as instituições de saúde mental estão implicadas na produção dos próprios objetos que pretendem extinguir.

Quais são os objetos da saúde mental no contemporâneo? Seriam eles os mesmos desde os tempos de Pinel, Esquirol, Kraeplim, Morel, e Falret? Para que o alienismo pudesse se manter de pé foi preciso produzir o asilo enquanto espaço que deu visibilidade ao poder do alienista, com sua estrutura arquitetônica e com as composições sonoras enunciativas que ali operavam cotidianamente. Não obstante, o fim do asilo não significa o fim das práticas asilares, que podem continuar a ocorrer nos espaços extramuros. Nos dias de hoje, no espaço das instituições de saúde mental, mesmo que não asilares, uma matéria-prima definida como mórbida é também modelada por dispositivos de "saúde mental". Entretanto, esses dispositivos insistem na cultura da "doença mental" em suas diversas modalidades, designadas a partir do DSM IV (classificação da Associação Psiquiátrica Americana), como "transtornos".

Estariam os corpos dos usuários sendo "modelados" assim como o corpo do louco foi modelado pelo asilo? Sabemos que o corpo do delinquente foi modelado pelas instituições prisionais - e ainda o é -; assim como o corpo dos alunos é modelado pelas instituições escolares. $\mathrm{O}$ processo de modelagem que se efetua em espaços específicos como os hospícios, as prisões e as escolas, por certo também ocorre nos dispositivos de saúde mental. Os usuários de hoje carregam marcas-vestígios das operações discursivo-teóricopráticas das filiações dos especialistas em saúde mental. Os especialismos são centros de poder que, nas suas múltiplas faces, produzem corpos-objetos, produção da matéria-prima que, doravante, circulará em meio aos saberes-práticas-discursos sacralizados e legitimados como universais. Diante dessa matéria-prima, os usuários terão pouca ingerência: não se lhes pergunta o que estão achando dos tratamentos que recebem ou das rotinas a que são submetidos.

\section{SAÚDE MENTAL, BIOPOLÍTICA E MODULAÇÃ̃O}

Que não se acusem os profissionais de saúde mental de serem autoritários, ou de imporem seus modelos de intervenção. As consultas iniciam-se com frequência com cândidas perguntas, como: “- o que iremos construir juntos hoje?" Alguns usuários como que se deixam hipnotizar pelas práticasdiscursos-saberes dos especialistas que se repetem como ladainhas nas rotinas diárias. Há também aqueles usuários que "resistem", não comparecendo a oficinas, faltando às consultas e a outras intervenções. Resistir à psiquiatria sempre foi tomado tradicionalmente como um dos mais graves sintomas de doença. Devemos, porém, considerar as faltas e desistências dos usuários em seu sentido político como resistências intercessoras agindo sobre as ladainhas dos centros do poder-saber psiquiátrico.

O controle em saúde mental pode ser tecido por essa dupla injunção: uma ação individualizante através de práticas-discursos-saberes que centripetizam a experiência sensível de cada 
usuário em ações docilizante-disciplinares. A outra ação mais ampla, biopolítica, é a ação globalizante da lógica biomédica difundida nas experiências sociais, apoiada na lógica psicofarmacológica que está disseminada nos corpos e nos ideários sociais. Decorre daí que há formas de poder em saúde mental, novas formas "biopolíticas", que se fazem não mais por modelagem, mas por modulação (Deleuze, 1992): A modulação, portanto, é uma espécie de regime de assujeitamento que se faz sem a necessária circunscrição no limite do corpo ou da instituição. "Sorria, você está sendo filmado!" Temos hoje uma forma de panoptismo molecularizado. Não precisamos mais de edifícios arquitetônicos para a vigilância. A vigilância, ela mesma, é feita à distância e também a partir da própria subjetividade de cada um. Subjetividades sintonizadas às frequências de uma sociedade que se quer produtiva, acética e livre de tudo o que possa dela diferir. Controlam-se os corpos através das regulações bioquímicas. Controlam-se as subjetividades mediante saberes-práticas terapêuticas nas quais os usuários não interferem. Controla-se ainda pela produção de uma memória funcional (Maciel, 2000) a partir do costume das consultas; da forma habitual dos processos terapêuticos; dos equipamentos asilares que os estabelecimentos de saúde mental reproduzem cronicamente.

\section{SAÚDE MENTAL E SUAS INSTITUIÇÕES}

Assinalemos os vetores principais que compõem uma cartografia ${ }^{2}$ (Kastrup, 2007) das instituições de saúde mental no contemporâneo.

a) Da instituição da doença: o objeto de trabalho dos profissionais de saúde mental ainda está ancorado na noção de doença mental. Cada um, filiado a uma ou outra escola teórica, compreende os fenômenos manifestados pelos usuários como psicopatológicos, fora da

2 Para Kastrup (2007), a cartografia é um método que visa acompanhar um processo, e não representar um objeto. Em linhas gerais, trata-se sempre de um processo de produção. De saída, a ideia de desenvolver o método cartográfico para utilização em pesquisas de campo no estudo da subjetividade se afasta do objetivo de definir um conjunto de regras abstratas para serem aplicadas. Não se busca estabelecer um caminho linear para atingir um fim. normalidade. Para Canguilhem (1978), normal vem de norma: norma vem de esquadro. O objeto final em saúde mental é o de eliminar o "erro psicopatológico" enquadrando-o em procedimentos pré-definidos.

b) Da instituição das classificações: uma das metas mais importantes do atendimento em saúde mental é referir as experiências sensíveis dos usuários a alguma unidade abstrata conceitual. Será preciso reduzir aquilo que se move diante das lentes dos especialistas a uma classificação para possibilitar a intervenção.

c) Da instituição da cronicidade: como de modo geral os especialistas reconhecem que os "tratamentos" não têm conseguido a "cura" dos transtornos, estes se destinam a controlar os sintomas, e frequentemente, a fazer com que cada um aprenda a conviver com a sua doença pelo resto da vida.

d) Da instituição do silêncio e da distância entre profissionais e usuários: todos os procedimentos institucionais se realizam sem participação da clientela atendida. A relação hierarquizada e dicotômica - usuário $\mathrm{x}$ profissional de saúde mental - é a regra. Jamais se leva em conta, nos serviços, alguma opinião ou sugestão dos usuários, embora muitos deles passem ali grande parte da vida. Outro aspecto da distância entre profissionais e usuários diz respeito a que estes últimos se colocam frequentemente na posição de quem nada sabe sobre sua própria vida, entregando-a às práticas e saberes dos profissionais.

e) Da instituição das terapias medicamentosas e psicoterapias como as únicas legítimas para o tratamento: nas instituições de saúde mental de hoje, ser tratado é receber uma receita de um médico-psiquiatra e ser escutado, geralmente, por um psicólogo. Outras modalidades de tratamento, como atendimentos em grupo, práticas do campo das oficinas terapêuticas, ligadas à arte, costumam não ser tomadas como tratamentos "de fato".

f) Da instituição da carreira de doente mental e da "procissão" de serviço em serviço: quando ingressam nos dispositivos de saúde mental os usuários iniciam uma carreira de doente mental. A lógica da doença mental é disseminada de forma avassaladora, não apenas no interior 
destes dispositivos, mas também nas experiências da cidade. A frustração das expectativas de ajuda efetiva para os problemas ou impasses que enfrentam faz com que estes iniciem uma "procissão" de serviço em serviço, de especialista em especialista. Essa busca faz parte da carreira de doente mental na qual ingressaram.

g) Da instituição do usuário "bate e pronto" e da "demanda invisível": os atendimentos costumam ter curta duração, impossibilitando que os usuários possam realmente ser escutados ou compartilhem suas experiências com o profissional. Podemos considerar essa prática também como um aspecto da relação usuárioprofissional, que produz efeitos de assujeitamento e distanciamento. Além disso, os estabelecimentos de saúde mental estão frequentemente lotados. Aqueles que chegam à recepção costumam receber a informação de que não há vagas e são remetidos a uma lista de espera ou recebem orientação para procurar outro serviço. O motivo pelo qual procuraram inicialmente o serviço não é escutado e vai sendo diluído, constituindo-se numa "demanda tornada invisível". O serviço de saúde mental desconhece sua demanda real, a qual é constituída pelos que nele não conseguem entrar.

A partir dessa cartografia podemos deduzir que a luta por um modelo substitutivo ao modelo hospitalocêntrico não pode se reduzir à diminuição dos leitos psiquiátricos através do fechamento destes centros e da criação de outras estruturas e dispositivos de saúde mental, tais como os Centros de Atenção Psicossocial. Nesses estabelecimentos, também estão presentes práticas como as que cartografamos, as quais ainda se ligam principalmente ao estabelecimento de uma carreira de doente mental. Lógicas manicomiais atravessam invisivelmente as práticas de saúde mental no contemporâneo. Derrubar os muros do hospício não pode ser nosso único objetivo, já que outras formas de manicomialização se instituem em meio às práticas em saúde mental.

\section{DA INVENÇÃO DE OUTRAS PERSPECTIVAS E PRÁTICAS}

Queremos, neste artigo, trazer à luz os centripetismos produzidos pelas práticas em saúde mental, bem como desvelar outras possibilidades e perspectivas. Que outras lentes poderemos colocar sobre as experiências sensíveis dos usuários? Há um eixo epistêmico que coincide com o processo dinâmico de constituição das configurações do "poder de ser afetado" de cada pessoa, ou com o modo como cada um expressa a sua "capacidade de ser afetado" ou a "capacidade de sofrer a força de afecção" daquilo que interfere num dado momento. Para Espinosa (1973), os seres existentes devem ser definidos pela sua capacidade de ser afetados. Ao invés de serem classificados por gêneros e espécies, poderão ser compreendidos pela capacidade singular de sofrer a ação dos encontros que fazem. Noutras palavras, cada modo existente será compreendido "por seu grau de potência", ou "por seu poder de ser afetado". A leitura das configurações do grau de potência de cada ser existente se expressa pelos afetos, emoções, desejos e ideias que estes expressam. Nas suas diversas modulações, essas expressões são as emergências transitivas dos modos existentes, elas mesmas efeitos dos encontros (Deleuze, 2002). Teremos a cada encontro, sempre uma nova configuração dos domínios imanentes a cada ser existente a partir da interferência dos novos encontros que faz. "Sofremos a força de afecção dos corpos exteriores permanentemente" (Deleuze, 1975), ou seja, é da natureza dos corpos sofrer no sentido de ser afetado por um outro corpo. Sofremos as ações de uma música; o poder de um olhar; as interferências de outras ideias e as ações dos alimentos que ingerimos. Sofremos as interferências dos nossos próprios sonhos, desejos, imagens, ideias. É parte da condição humana, portanto, sofrer as interferências de heteróclitos domínios - sejam eles constituintes do plano do coletivo ou dos domínios imanentes a cada ser existente.

Decorre deste plano de interferências a emergência de existências complexas que têm sua gênese na experiência sensível, a qual expressa o poder de ser afetado de cada ser e se constitui de uma diversidade de domínios: domínio biológico; domínio psíquico; domínio sensível-perceptivo; domínio emocional-afetivo; domínio energético, domínio espiritual. Toda existência é complexa, uma vez que as interferências entre domínios efetuam-se o tempo todo. Seria ingênuo afirmar que as emoções e afetos estão desencarnados das produções bioquímicas do cérebro e de outros inúmeros processos biológicos, mas também não 
podemos reduzi-las a mero epifenômeno dos processos bioquímicos. "Emoção" é "ato de mover"; perturbação ou variação do espírito advinda de situações que podem se manifestar de diversas formas, como alegria e tristeza; reação intensa e breve ou mais duradoura do organismo ao inesperado, acompanhada de um estado afetivo penoso ou agradável, ou despertado por sentimentos estéticos, religiosos, etc. Como podemos verificar, a emoção, ela própria, nasce dos encontros. Sem os encontros, as marés químiconeurais não poderiam modular a usina química da qual elas mesmas fazem parte. Há uma política dos encontros que cada ser existente deve traçar, na relação recíproca com os corpos afetantes exteriores, agindo de modo a potencializar o plano da vida; uma política das interferências que gera a diversidade a partir do encontro. É pelo entrelaçamento das diversidades existenciais que são engendrados os domínios que constituem cada existência singular.

Somos seres complexos. É pelas lentes da complexidade que tecemos a nossa existência na relação com outros corpos que nos afetam. Assim, podemos afirmar que a proposta da terapia medicamentosa, de modular as marés químiconeurais de modo a produzir estabilidade, torna-se um trabalho árduo, pois somos afetados permanentemente pela forças de afecção dos encontros de corpos, sofrendo a ação do que é atual e contemporâneo e que modulará a complexidade de domínios que interferem na nossa existência. Essa interferência de outros corpos produz marcas e vestígios, fazendo com que o que estava fora se torne parte da nossa existência.

Desejamos com este artigo contribuir para a construção de leituras das experiências sensíveis pelas lentes da complexidade, perspectiva que deveria nortear sempre as práticas em saúde mental. Desejamos produzir um plano onde interferências entre o plano dos saberes e o plano das práticas produzam misturas que os tornem mais complexos e assim capazes de se aproximar e intervir nas existências singulares dos que buscam hoje os serviços de saúde mental. Desejamos que os especialistas possam sair de sua postura acética, que não lhes permite colocar em análise os saberes e práticas aos quais estão filiados. Desse modo acreditamos que as experiências sensíveis dos usuários poderão merecer outras leituras que possam referi-las a existências complexas, e os saberes instituídos em saúde mental poderão, por sua vez, sofrer a força de afecção de outros saberes, expandindo-se para além de suas fronteiras.

A complexidade singular de um dado saber é tecida pela corporação dos afiliados que sustenta sua lógica. No entanto, um dado domínio de saberfazer que se feche em si poderá sofrer um ensimesmamento cronificador, produzindo ilusões como a de ser o único saber legítimo e universal. O principal efeito deste processo de cronificação e isolamento é a produção de reducionismos e o afastamento das experiências sensíveis e coletivas. Como seria se, ao contrário, as muitas teoriaspráticas em saúde mental sofressem a ação de outros saberes-fazeres - incluindo-se aqui saberesfazeres de outras áreas, como a das artes, a da filosofia, o saber das pessoas comuns e outros domínios habitualmente considerados como nãoclínicos?

Estabelecer ressonâncias entre os campos da arte, da filosofia, da política construindo outras clínicas, para que possamos melhor compreender as complexidades do cotidiano, superando a cronificação das teorias e práticas em saúde mental e os reducionismos que as afastam da dimensão do coletivo; incluir os saberes do chamado senso comum e as vozes dos "usuários" abrindo espaços de participação coletiva nos serviços - tais poderiam ser os objetivos de uma clínica transdisciplinar como meio sempre provisório de superação dos reducionismos, dos tecnicismos e dos individualismos que atravessam o campo do que hoje se denomina saúde mental.

\section{REFERÊNCIAS}

Aguiar, A. A de (2004) Psiquiatria no Divã: Entre as Ciências da Vida e a Medicalização da Existência. Rio: Relume Dumará.

Canguilhem, G (1978) O Normal e o Patológico. Rio: Forense Universitária.

Deleuze, G., \& Guattari, F. (1977). Dialogues. Paris, Flammarion.

Deleuze, G., \& Guattari, F. (1974). O Anti-Édipo: Capitalismo e Esquizofrenia. Rio, Imago,

Deleuze, G. (2002) Espinosa e a Filosofia Prática. São Paulo: Escuta.

Deleuze, G. (1992) Pós-Scriptum sobre a Sociedade de Controle. Em Conversações. Rio: Editora 34.

Deleuze, G. (1975) Spinoza y el Problema de la Expresión. Barcelona: Muchaik editores. 
Espinosa, B. (1973). Ética. Os Pensadores Volume XVII. São Paulo: Abril Cultural.

Foucault, M. (2005) A arqueologia do Saber. Rio: Forense Universitária.

Hochmann, J. (1971) Hacia uma psiquiatria comunitaria. Buenos Aires: Amorrortu.

Kastrup, V. (2007) O Funcionamento da Atenção no Trabalho do Cartógrafo. Psicologia \& Sociedade (19) 1, 15 -22.

Maciel Junior, A. (2000) Nomadização dos espaços Urbanos. Em Thiesen, M. C. I e Gondar, J. (Org.) Memória e Espaço.Rio de Janeiro: Viveiros de Castro.
Morana, H. (2003). Identificação do Ponto de Corte PCJ-R (Psychopaty Checklist Revised) em População Forense Brasileira. Caracterização de dois subtipos de personalidade: transtorno global e parcial.Tese de doutorado não publicada. Faculdade de Medicina da Universidade de São Paulo, São Paulo.

Szasz, T. (1978) Fabricação da Loucura - um estudo comparativo entre a Inquisição e o movimento da Saúde Mental. Rio de Janeiro: Zahar Editores.

Recebido em 20/12/2007 Aceito em 12/08/2008

Endereço para correspondência : Cristina Rauter, R. Major Fróes 225 São Francisco, CEP 24365030, Niterói-PR, Brasil. E-mail: rauter@terra.com.br 